\title{
Lexical frequency and exemplar-based learning effects in language acquisition: evidence from sentential complements
}

\author{
Evan Kidd $^{\mathrm{a}, \mathrm{c}, *}$, Elena V.M. Lieven ${ }^{\mathrm{a}, \mathrm{b}}$, Michael Tomasello ${ }^{\mathrm{b}}$ \\ ${ }^{a}$ School of Psychological Sciences, La Trobe University, Bundoora 3086, Victoria, Australia \\ ${ }^{\mathrm{b}}$ Max Planck Institute for Evolutionary Anthropology, Leipzig, Germany \\ ${ }^{\mathrm{c}}$ School of Psychological Science, The University of Manchester, Oxford Road, Manchester M13 9PL, UK
}

Accepted 10 May 2009

\begin{abstract}
Usage-based approaches to language acquisition argue that children acquire the grammar of their target language using general-cognitive learning principles. The current paper reports on an experiment that tested a central assumption of the usage-based approach: argument structure patterns are connected to high frequency verbs that facilitate acquisition. Sixty children $(N=60)$ aged 4- and 6-years participated in a sentence recall/lexical priming experiment that manipulated the frequency with which the target verbs occurred in the finite sentential complement construction in English. The results showed that the children performed better on sentences that contained high frequency verbs. Furthermore, the children's performance suggested that their knowledge of finite sentential complements relies most heavily on one particular verb think, supporting arguments made by Goldberg [Goldberg, A.E., 2006. Constructions at Work: The Nature of Generalization in Language. Oxford University Press, Oxford], who argued that skewed input facilitates language learning.

Crown Copyright @ 2009 Published by Elsevier Ltd. All rights reserved.
\end{abstract}

Keywords: Exemplar-based learning; Finite sentential complements; Usage-based language acquisition

\section{Introduction}

How children come to identify and restrict grammatical regularities in their target language is a major challenge for functionalist theories of language acquisition that do not assume that children possess substantial innate grammatical knowledge. The usage-based or emergentist approach appeals to children's ability to extract statistical regularities from the input (Goldberg, 2006; MacWhinney, 1998; Tomasello, 2003). In the current paper we test two of the predictions of the usage-based approach: (i) children's syntactic knowledge is intimately tied to their lexical knowledge and the frequency with which verbs appear in syntactic constructions, and (ii) children learn argument structure patterns through exemplar-based learning. We consider each of these predictions in turn.

\footnotetext{
* Corresponding author. Present address: School of Psychological Sciences, La Trobe University, Bundoora 3086, Victoria, Australia. Tel.: +61394792420.

E-mail address: e.kidd@latrobe.edu.au (E. Kidd).
} 
There exist a number of empirical demonstrations that children's early grammatical knowledge is intimately connected to frequent lexical items. Work by Tomasello and colleagues has shown that children are generally quite conservative in their early use of verb argument structure constructions. For instance, Tomasello (2000) reported on a series of studies that showed that young children who are trained on novel verbs do not readily generalise their use to new syntactic environments until they are aged 3.0 and over. For example, when trained on the novel verb meek in an intransitive frame (e.g., Ernie is meeking!), children under 3-years are unlikely to generalise the use of the verb to a transitive construction (e.g., Ernie is meeking Bert). Such lexical conservatism has been argued by Lieven et al. (1997) to reflect the fact that children do not operate with formal syntactic categories from the beginning of acquisition, but instead learn limited scope lexical frames that are eventually redescribed into an adult-like grammar.

Just as highly frequent lexico-constructional pairings constitute children's first productions, the frequency with which lexical items occur in syntactic constructions appears to play a key role in the process of forming grammatical generalisations. For instance, Matthews et al. $(2005,2007)$ showed that English- and Frenchspeaking children were more likely to correct ungrammatical transitive sentences that contained high frequency verbs (e.g., The dog the seal pushed $\rightarrow$ The dog pushed the seal) than those that contained less frequent ones. Similarly, Brooks et al.(1999), Theakston (2004) and Ambridge et al. (2008) have all shown that children are less likely to make verb argument structure generalisation errors on sentences containing high frequency verbs compared to their performance on sentences containing low frequency verbs.

Such frequency effects are considered to be a marker of the entrenchment process, whereby it is claimed that children gradually learn the selectional restrictions of individual verbs by tracking their use in different syntactic environments. Goldberg (2006) has instead attributed such effects to the process of statistical pre-emption, where the claim is that children are protected from inducing an overly general grammar because the use of a verb in one or more syntactic environments (e.g., He fell, She made him fall) decreases the likelihood that it will occur in other argument structure patterns (e.g., * She fell him). It is most likely that these two processes work in tandem to guide acquisition, and we will make no attempt to disentangle the effects here.

Most of the acquisition work to date has focussed on the issue of verb argument structure acquisition by concentrating on simple sentences. However, Kidd et al. (2006) showed that the same principles apply to the acquisition of more complex argument structure patterns: finite sentential complements (see also Kidd, 2006). They asked 3-5-year-old English-speaking children to repeat finite sentential complement constructions that were manipulated for the frequency with which the main verb appeared in this construction relative to its total use in the language. They showed that the children were better able to remember and repeat the test sentences that contained the high frequency verbs than those that contained low frequency verbs. This result was interpreted to support the notion that children's knowledge of complementation is at least partially lexically-bound. Specifically, the frequency with which a given complement-taking verb (CTV) occurs in a finite sentential complement construction (i.e., Pr(Construction|Verb)) predicts children's ability to produce this sentence type. Such an effect can be considered to be a vestige of the entrenchment process, and also a reflection of the lexical nature of children's language processing machinery, since similar effects have been reported in the adult sentence processing literature (Garnsey et al., 1997; Holmes et al., 1989; Trueswell et al., 1993).

Kidd et al. (2006) also observed another effect, the results of which provided evidence supporting the suggestion that children engage in exemplar-based learning during acquisition. When the children repeated the test sentences, they did not always use the CTV from the test structure. Instead, they made many main verb substitutions, but did not do so at random. They most often inserted high frequency verbs into their repetitions, which complemented the repetition data. However, they most often substituted the CTV think into their repetitions, which constituted $58 \%$ of the children's overall substitutions $(67 \%$ for the younger children; $47 \%$ for the older children). Think has special status in English as a CTV, since it is used very frequently and is grammatical only in a finite sentential complement construction, discounting examples of VP-ellipsis in frozen phrases such as I think so. Furthermore, although clearly a mental state verb, think has special status amongst English CTVs because it has an arguably separate and highly frequent role as an epistemic marker (see Thompson, 2002; Thompson and Mulac, 1991). For instance, it has been noted that many utterances containing think are of the form I think + PROPOSITION, where the semantically empty main clause serves to mark the extent to which the speaker is certain about the proposition contained in the subordinate clause. This construction constitutes the first finite sentential complements produced by young English-speaking children 
(Diessel and Tomasello, 2001; for a similar example from German see Brandt et al. (unpublished manuscript)). Following Diessel and Tomasello (2001), this is likely to be the case because these utterances are frequent and are less syntactically and semantically complex than true finite sentential complements, which are less syntactically integrated and require the attribution of unobservable mental states to participants in discourse.

Kidd et al. (2006) suggested that, for these reasons, highly frequent finite sentential complement constructions containing think might act as an exemplar for children learning this construction. Dabrowska et al. (2009) have argued along similar lines for long distance dependencies such as Who do you think will win Wimbledon?, and reported similar verb substitution effects using the imitation technique. The notion of exemplarbased learning has empirical support in the literature (for a theoretical discussion see Abbot-Smith and Tomasello, 2006). For instance, work by Goldberg and colleagues (Casenhiser and Goldberg, 2005; Goldberg, 2006; Goldberg et al., 2004, 2005) has shown that many constructions contain one high frequency verb that accounts for the 'lion's share' of tokens in that construction. For example, for the dative the most frequent verb is give. Goldberg (2006) argued that these verbs have special status because they are semantically general and closely embody the meaning of the argument structure construction in which they most often occur. For instance, the semantics of give most closely matches the semantics of the dative - object transfer.

Although the results reported by Kidd et al. (2006) and Dabrowska et al. (2009) are suggestive, they are limited in one crucial manner. Since think was used in both of their experimental materials, it is possible that the children most often produced this verb not only because it is the most frequent CTV that occurs with finite sentential complements in English, but also because its presence in the experimental materials lead it to be primed in the children's recall of the sentences. A stronger argument could be made for think as an exemplar if children use the verb in their recall of sentences even if they have not heard it in the experimental materials. The current study tested this proposal.

The aims of the current study were to investigate (i) the role of CTV frequency in children's production of finite sentential complements, and (ii) the role of think as a possible exemplar in the acquisition of this construction. Children aged 4- and 6-years participated in a sentence recall/lexical priming task. In the task, children were presented with pictures that were described by a finite complement clause construction that contained either a high frequency (HF) or low frequency (LF) CTV; this was the target sentence and children were informed that they would have to remember how to describe that picture (i.e., remember the target sentence). They were then presented with another picture that was again described by a finite complement clause construction. This was the prime sentence, which differed from the target sentence due to the fact that it contained a CTV matched for semantic similarity but contra-matched for frequency. That is, if the target sentence contained a HF CTV, the prime sentence contained a LF CTV, and vice-versa. Following the presentation of the prime sentence and picture, the children were shown the target picture again and were required to recall the target sentence. This manipulation was intended to systematically examine the main verb substitution effect found in Kidd et al. (2006). Following Kidd et al., it was predicted that children would be better able to recall target sentences that contained HF CTVs than those that contained LF CTVs. It was also predicted that children would be more susceptible to HF prime verbs than LF prime verbs, such that they would insert HF prime verbs into their recall of target sentences more often than they would insert LF prime verbs. The rationale behind these predictions is that, following the usage-based approach, HF CTVs should be more strongly associated with this syntactic frame, whereas the LF CTVs should not be. Finally, since none of the experimental sentences contained think, we explored the possibility that this verb serves as an exemplar verb for the finite sentential complement construction by investigating whether children inserted this verb into their recall of the target sentences.

\section{Method}

\subsection{Participants}

Sixty children $(N=60)$ participated in the study: 304 -year-olds (mean age: 4.4 , range: $4.0-4.11)$ and 306 year-olds (mean age: 6.5 , range: $5.8-7.0$ ). The children were recruited from a registry of children at the Max Planck Child Study Centre at the University of Manchester, and from a primary school in the local 
Manchester metropolitan area. None had any known language impairment or learning difficulty. Two 4-yearold children did not produce any analysable data and so were excluded from the final sample.

\subsection{Materials}

Four CTV pairs manipulated for frequency were used. The frequency count was the frequency with which each verb appeared in a finite that complement clause relative to its overall use in the language. The frequency counts were computed using the CHILDES database (MacWhinney, 2000). The HF CTVs were taken from Kidd et al. (2006) and paired with LF CTVs from the same semantic class (Levin, 1993). The verb pairs were say-claim, know-believe, hope-feel, bet-wager (HF CTVs first). Two of the HF CTVs in this study were LF CTVs in Kidd et al:: say and know. There were two reasons why these were used as HF CTVs. First, as noted above, think was excluded. Second, we wanted to use CTVs that could only take finite sentential complements. Thus see, which was used in Kidd et al., was not appropriate. Since children performed relatively well on sentences containing these verbs in Kidd et al., know and say were chosen as HF CTVs. A corpus study conducted on the Manchester CHILDES corpus (Theakston et al., 2001) confirmed that the LF CTVs rarely, if ever, occur in complement clause constructions in the speech of young children from the speech community from which we drew our sample (see Table 1). The rationale for using such low frequency verbs was to provide a strong test of children's abstract knowledge of complementation, as when, for instance, novel words are employed to test children's knowledge of syntactic categories.

From these eight verbs 16 test sentences were constructed. These were paired with prime sentences that were also complement clause constructions, but differed in lexical content from the target and, crucially, contained the matched CTV from the verb pair (see Appendix A). An example test-prime pair is shown in (1):

(1) Test: Mickie says Minnie is wearing a lovely dress.

Prime: Shrek claims Donkey is talking too much.

All sentences contained third person lexical NPs because they described pictures. They did not contain the optional complementiser that because it rarely appears in children's speech (Diessel, 2004). There were also 16 filler sentences. The pictures that the test and prime sentences described were constructed from clip art of cartoon characters familiar to children of the age tested. Each sentence had its own unique picture. There were 54 pictures in total: six practice, 32 test (16 target-prime pairs), and 16 filler pictures.

\subsection{Procedure}

The children were tested individually in a laboratory at The University of Manchester or in a quiet space in their school. The task was introduced to the child using three practice items that followed the exact same format as the test items. That is, the child was shown a target picture that was described by the experimenter. The child was then asked to repeat the sentence verbatim. Once the child had done this, the experimenter showed the child the next picture (the prime picture in the test trials) and described it using the prime sentence. The child was told that 'this was the experimenter's turn to describe a picture', and that 'they shouldn't repeat this one'. The child was then shown the original target picture and was asked to recall the original description. Testing lasted approximately $25 \mathrm{~min}$.

Table 1

Frequencies for verbs appearing in a finite sentential complement construction (numerator) relative to each verb's total use in the corpus (denominator).

\begin{tabular}{llllll}
\hline HF CTV & Frequency count & Relative frequency & LF CTV & Frequency count & Relative frequency \\
\hline Bet & $36 / 51$ & .71 & Wager & $0 / 0$ & 0 \\
Hope & $17 / 30$ & .57 & Feel & $0 / 32$ & 0 \\
Say & $173 / 474$ & .28 & Claim & $0 / 0$ & 0 \\
Know & $78 / 1668$ & .05 & Believe & $0 / 1$ & 0 \\
\hline
\end{tabular}




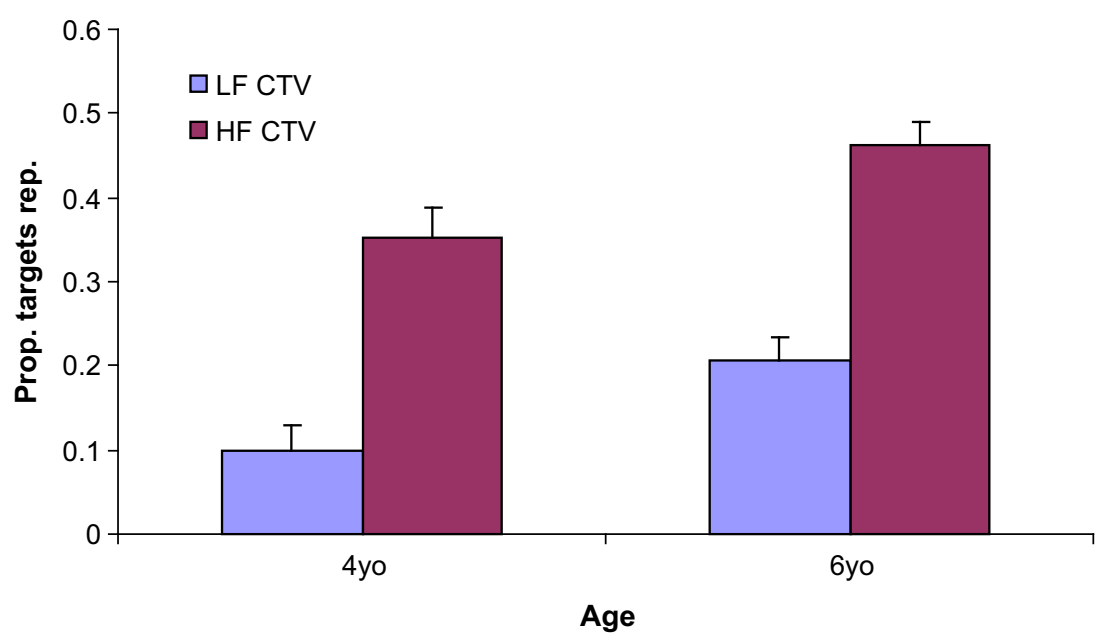

Fig. 1. Mean proportion (and SES) of repetitions of target sentence by age and CTV frequency in the target.

\section{Results}

The children's recall of the target sentences were transcribed and coded. Only valid responses, where the children produced a finite sentential complement, were analysed. Overall, the 4-year-olds produced $83 \%$ (398/480) finite sentential complements; the 6-year-olds produced 95\% (456/480). ${ }^{1}$ There were three dependent measures of interest: (i) the proportion of exact repetitions, (ii) the proportion of trials that the children inserted the prime verb into their repetition, and (iii) the total number and types of other main verb substitutions that the children made (i.e., repetitions that contained main verbs other than the target or prime CTV).

The children's repetitions of the target sentence were analysed first. An utterance was counted as a repetition if the surface form of the test sentence was preserved. For instance, for the test sentence Mickie says Minnie is wearing a lovely dress, (2) was counted as a repetition but (3) was not, since (2) preserves the $[\mathrm{NP}-\mathrm{V}-[\mathrm{NP}-\mathrm{V}-\mathrm{NP}]]$ surface form and the semantics of the test sentence, whereas (3) does not because it fails to mention both participants in the sentence. Therefore, although (3) is finite complement clause, its reduced form deviates too much from the surface form of the target to constitute a repetition.

(2) Mickie says Minnie's got a lovely dress.

(3) Mickie says it's a lovely dress.

The proportion of repetitions of the target sentence was calculated by dividing the total number of repetitions by the total number of valid responses (i.e., total repetitions/total number of attempts at repetition that were finite complement clauses). The means and standard errors for each group by CTV frequency of the target are shown in Fig. 1.

Fig. 1 shows that both groups better recalled the target sentences that contained HF CTVs than those that contained LF CTVs $\left(F_{1}(1,56)=72.45, p<.001\right.$, partial $\eta^{2}=.564, F_{2}(1,28)=20.48, p<.001$, partial $\left.\eta^{2}=.422\right)$. The difference was significant for both age groups $\left(6\right.$ yo: $t_{1}(29)=5.35, p<.001, t_{2}(14)=2.99$, $p=.01$; 4yo: $\left.t_{1}(27)=6.82, p<.001, t_{2}(14)=3.41, p=.004\right)$. Overall, the 6-year-old children provided more repetitions of the target than the 4-year-old children $\left(F_{1}(1,56)=8.74, p=.005\right.$, partial $\eta^{2}=.135$, $F_{2}(1,28)=4.71, p=.039$, partial $\left.\eta^{2}=.144\right)$.

Fig. 2 shows the proportion of trials on which children inserted the prime verb into the recall of the target by age and CTV frequency of the prime. This dependent measure was calculated by dividing the total number

\footnotetext{
${ }^{1}$ Non-valid responses were typically items where children failed to recall any of the target responses (e.g., I don't know, I forgot) or provided paraphrases of the subordinate clause (e.g., Minnie's got a nice dress).
} 


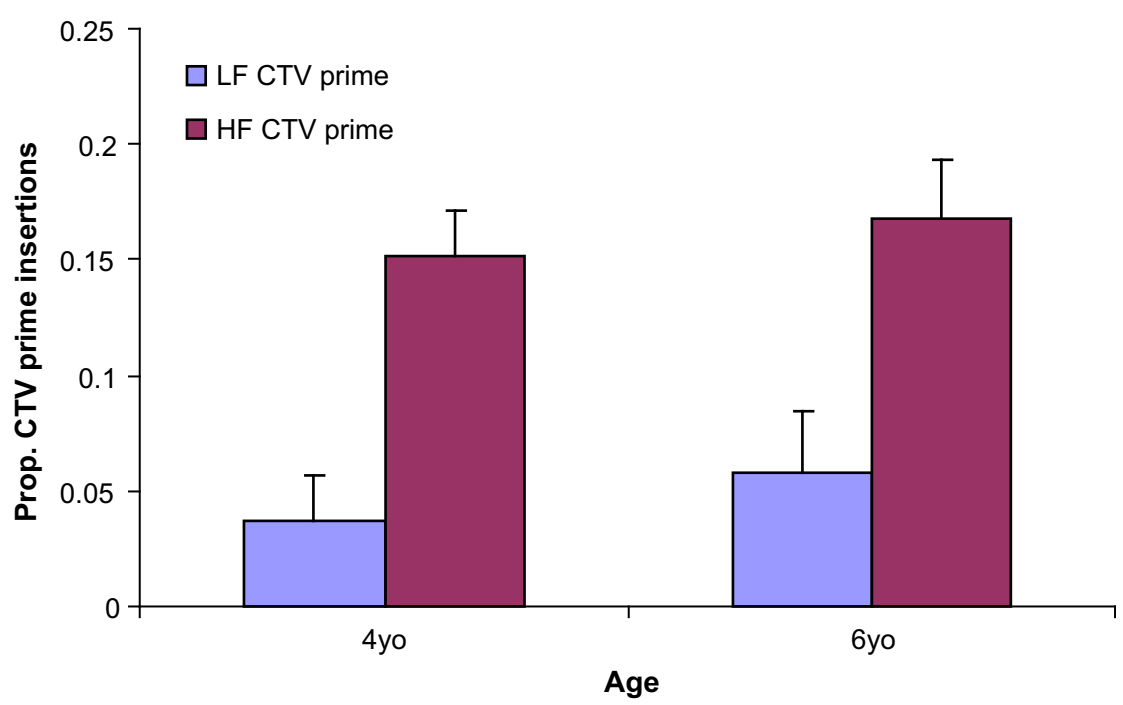

Fig. 2. Mean proportion (and SES) of trials the prime CTV was substituted into the target sentence by age and frequency of the CTV prime.

of finite sentential complement repetitions that contained the prime verb (in that trial) by the total number of valid responses.

Children in both age groups were more likely to substitute a HF prime into their recall of the target than a LF prime $\left(F_{1}(1,56)=35.35, p<.001\right.$, partial $\eta^{2}=.387, F_{2}(1,28)=15.72, p<.001$, partial $\left.\eta^{2}=.36\right)$. The difference was significant for both age groups (6yo: $t_{1}(29)=4.24, p<.001, t_{2}(14)=2.15, p=.049$; 4уо: $\left.t_{1}(27)=4.18, p<.001, t_{2}(14)=3.91, p=.002\right)$. No other effects were significant.

\subsection{Other main verb substitutions}

The children substituted verbs other than the experimental verbs into their recall of the test sentence. This accounted for $35.9 \%$ of the 4-year-olds' valid responses (143/398), and $29.6 \%$ of the 6-year-olds' valid responses (135/456). Fig. 3 shows the proportion of valid trials in which the children inserted a new CTV for both frequency conditions.

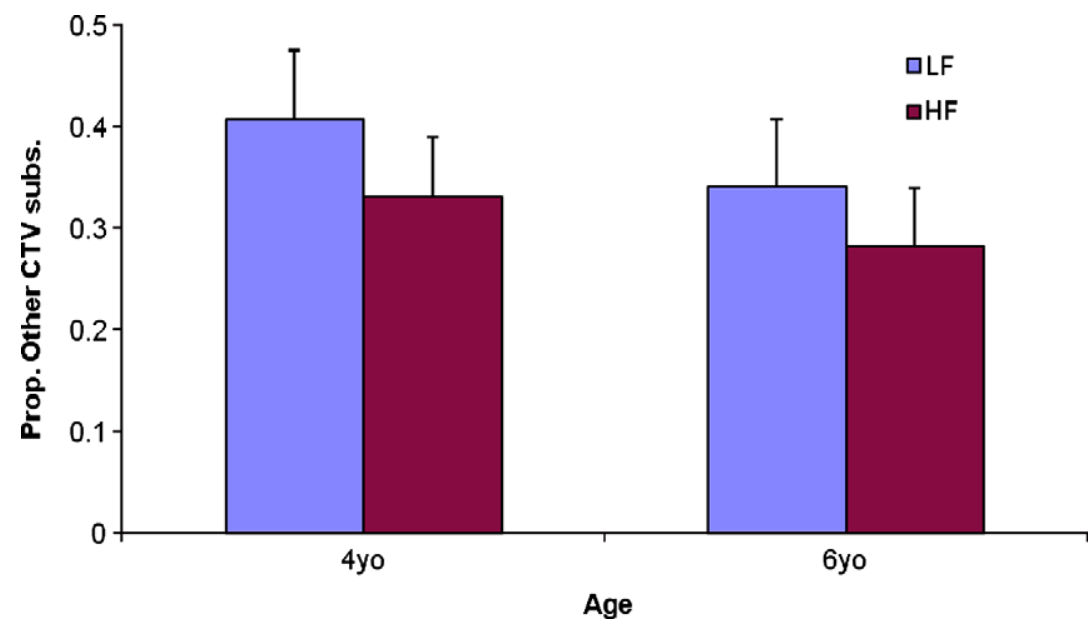

Fig. 3. Mean proportion (and SES) of CTV substitutions by frequency of the CTV in the target sentence and age. 
Fig. 3 shows that both the 4-year-old and 6-year-old children made more 'other' main verb substitutions when the target sentence contained a low frequency CTV than when it contained a high frequency CTV. A 2 (age: 4- vs. 6-year-olds) by 2 (frequency of CTV in the target: High vs. Low) revealed a significant effect of frequency that was only reliable by participants $\left(F(1,56)=5.12, \quad p=.028\right.$, partial $\eta^{2}=.084$; $F_{2}(1,28)=2.2, p=.153$, partial $\eta^{2}=.072$ ). The effect was only reliable for the 4-year-old children (4yo: $\left.t_{1}(27)=2.06, p=.025 ; t_{2}(14)=1.06, p=.15\right)$; 6yo: $t(29)=1.27, p=.11 ; t_{2}(14)=1.03, p=.16$. There were no other significant effects.

Although the fact that children inserted other CTVs into their repetitions is interesting in itself, they did not insert any CTV at random. In fact, a majority of the children's CTV substitutions involved just one verb - think. For the 4-year-olds, think constituted 88\% (126/143) of their other CTV substitutions, and was therefore used in $31.7 \%$ of their valid attempts to recall the target sentence (126/398). For the 6-year-old, think constituted $75 \%(102 / 136)$ of their other CTV substitutions, which was $22.4 \%$ of their valid attempts to recall the target sentence (102/456). The use of think was not limited to a few children in each age group. In the 4-year-old group, 20/28 children produced at least one token of think $(M=4.5, S D=5.1$, range: $0-15)$, and in the 6 -year-old group $22 / 30$ children produced at least one token $(M=3.4, S D=3.8$, range: $0-14)$.

A full list of the children's 'other' CTV substitutions for each age group is listed in Appendix B.

\section{Discussion}

Our hypotheses were supported. Firstly, the children were better able to recall the test sentences that contained HF CTVs than those that contained LF CTVs. Secondly, they were more likely to insert a HF prime verb into their recall of the target sentence. Finally, the children from both age groups inserted think into their recall of the target sentence, despite the fact that this verb was not in the test materials. We discuss these results in turn.

The results suggest that children's knowledge of complementation is linked to their knowledge of individual lexical items. There are several possible explanations for how this lexical and grammatical knowledge might be related. In the first instance, it is possible that the children's knowledge of finite complement clauses is still lexically-specific and bound to high frequency CTVs. That is, children's knowledge of complementation is solely attributed to their acquisition of high frequency lexico-constructional pairings. In its strongest form this explanation suggests that children only have verb-specific information and that they do not have an abstract representation for the construction. Although lexical effects such as those observed in the current study could be interpreted in this manner, we suggest that even 4-year-olds must have some abstract knowledge of this construction. Children begin to use this construction in a restricted form in their third year of life, and make frequent use of them after their third birthday (Diessel, 2004). On the usage-based approach, repeated use of this construction will result in the sentence-level form being associated with a meaning. With increased variation of the lexical items contained within the construction (e.g., nouns, verbs, use of complementiser), children's representation of the form will become more abstract, as will the semantics of the construction. We return to the discussion of abstraction below.

Instead, it is more plausible that the lexical effects in the data reflect the lexical nature of structure building and the fact that the children have had more experience with HF CTVs. Verbs play a crucial role in the syntax of a sentence; most theoretical accounts now argue for an enriched lexicon where lexical items are tagged with information about what argument structure constructions they can inhabit (e.g., Bresnan, 2001; Goldberg, 1995; Pollard and Sag, 1994). This move has been paralleled by advances in theoretical approaches in adult psycholinguistics, where models of sentence processing now argue for the lexical projection of grammar (e.g, MacDonald et al., 1994; Trueswell and Tanenhaus, 1994). On such an approach, our data could be explained as simultaneously reflecting the fact that children possess at least partially abstract knowledge of sentential complements, but that they perform differently on sentences containing verbs of varying frequency because they must learn the individual argument structure privileges of each verb. This explanation is consistent with the fact that adults show lexical frequency effects in adult 
comprehension, as shown in reading time studies (Garnsey et al., 1997; Holmes et al., 1989; Trueswell et al., 1993). The approach also predicts that children's acquisition of low frequency (and hence later acquired) CTVs will be more rapid than during early acquisition, since their existing knowledge of the construction will enable them to categorise new instances faster. McClure et al. (2006) have shown such facilitation to occur for later acquired verbs in young children's acquisition of the English intransitive and transitive constructions.

A feature of the usage-based approach to language is that generalisations co-exist amongst item-based constructions (Diessel, 2004; Verhagen, 2005). The second major finding of the present study was that, despite that fact that think was not included in the experimental materials, the children still produced this verb in their recall of the test sentences, and did so very frequently. Given that there was clearly a memory-based component to the task, this result suggests that when children lost a full verbatim memory trace for the target sentence, they used the structural cue of the construction to recover what is arguably the most important lexical item - the main verb. That is, they computed $\operatorname{Pr}[\operatorname{Verb} \mid$ Construction]. Sometimes the verb that they inserted was the prime verb, and other times it was a different verb, but most often it was think. This suggests that there is something special about think in the finite sentential complement construction, and we suggest that in this instance it acts as an exemplar for children in acquisition. That is, just as in English give acts as an exemplar verb for the dative construction because it is frequent and its semantics closely matches the constructional meaning of object transfer, we suggest that think is an exemplar for finite sentential complements for the same reasons.

How do linguistic exemplars facilitate language acquisition? Abbot-Smith and Tomasello (2006) argue for a hybrid model of linguistic categorisation that identifies a central role for exemplar-based learning. They argue that children's early language, which is lexically-specific, can be categorised as exemplar-based learning. New instances of the construction can be categorised by comparisons to the exemplar on the basis of form and function. Additional novel utterances are then categorised by comparison to the set of the utterances that instantiate a construction. The greater the size of the set, the greater the likelihood of generalisation, such that abstract grammatical schemas represent an immanent or emergent property of the set (see also Langacker, 2000). On this approach pervasive exemplars such as $N P$-think-S still play a role in linguistic behaviour because they are not discarded; instead, the principle of entrenchment predicts that these tokens will be strengthened with use. This prediction is supported by data from Dabrowska et al. (2009), who even observed exemplar-type effects for this construction in adults.

To conclude, we have provided additional evidence to suggest that children's language acquisition is driven by lexical learning, even in more complex cases such as finite sentential complements. Additionally, we have provided strong evidence for an exemplar-based learning account for this construction, as evidenced by children's use of the high frequency verb think in their recall of the test sentences, which never contained this verb. Such effects are consistent with the usage-based approach to acquisition and linguistic representation. Of course, we are not claiming that these are the only variables that contribute to learning this construction. Since complement clauses require main verbs that encode mental states, other non-linguistic factors such as an understanding of mind states will almost certainly play a role in acquisition and use (e.g., Astington and Jenkins, 1999; Bartsch and Wellman, 1995). Our suggestion is therefore that lexical frequency information and exemplar-based learning play a significant role in the acquisition of finite sentential complements.

\section{Acknowledgements}

This research was supported by a postdoctoral fellowship from the Max Planck Institute for Evolutionary Anthropology and a Charles La Trobe Research Fellowship to the first author. We would like to thank the staff and pupils at St. Catherine's Primary School for participating in this study, Lorna Fontaine for help with testing, and three anonymous reviewers for helpful comments. 


\section{Appendix A. Experimental items}

Say-Claim (HF target, LF prime)

(1)

Claim-Say (LF target, HF prime)

Know-Believe (HF target LF prime)

Believe-Know (LF target, HF prime)

Hope-Feel (HF target, LF prime)

Feel-Hope (LF target, HF prime)

Bet-Wager (HF target, LF prime)

Wager-Bet (LF target, HF prime)
Mickie says Minnie is wearing a lovely dress.

Prime: Shrek claims Donkey is talking too much.

Donald says Nemo is swimming very fast.

Prime: Simba claims Pinocchio is resting too much.

Nemo claims Mickie is painting a picture.

Prime: Minnie says Donald is going to the shop.

Bob claims Mickie also builds good things.

Prime: Mickie says he forgot something.

Mr. Bump knows Mr. Tall can reach high things.

Prime: Paddington believes he can ski.

Nemo knows Shrek likes eating yummy food.

Prime: Mr. Jelly believes he is jumping very high.

Paddington believes Minnie is going to the dance.

Prime: Ham knows Mickie likes running.

Mr. Tickle believes Mr. Small can jump high.

Prime: Mr. Noisy knows he can yell loudly.

Bob hopes Wendy wants a cup of tea.

Prime: Mr. Snow feels the sun likes shining.

Nemo hopes Bob is fixing his new house.

Prime: Rex feels Tigger is jumping too high.

Mr. Bump feels Mr. Messy is smiling at him.

Prime: Pluto hopes the sun is shining tomorrow.

Minnie feels Mickie will give her the flower.

Prime: Woody hopes Mr. Funny will make him laugh.

Mickie bets Pluto will bark very loudly.

Prime: Mr. Tall wagers Mr. Bump will fall over.

Goofy bets Donald will run to the shop.

Prime: Mickie wagers Paddington will paint the wall.

Donald wagers Buzz will fly to the moon.

Prime: Mr. Tickle bets he will make Pluto laugh.

Mr. Tickle wagers Donald will quack loudly.

Prime: Shrek bets Potato Head will make a silly face. 


\section{Appendix B}

Types and frequencies of 'Other' CTVs produced by the children in their recall of the target sentence.

\begin{tabular}{lll}
\hline Verb & 4yo & yo \\
\hline Think & 126 & 102 \\
Find & 0 & 2 \\
Get & 1 & 0 \\
Laugh & 0 & 1 \\
Like & 0 & 2 \\
Nonword & 4 & 7 \\
Persuade & 0 & 1 \\
Reckon & 0 & 13 \\
See & 3 & 5 \\
Tell & 3 & 1 \\
Wish & 6 & 1 \\
Total & 143 & 135 \\
\hline
\end{tabular}

\section{References}

Abbot-Smith, K., Tomasello, M., 2006. Exemplar-learning and schematization in a usage-based account of syntactic acquisition. The Linguistic Review 23, 275-290.

Ambridge, B., Pine, J.M., Rowland, C.F., Young, C.R., 2008. The effect of verb semantic class and verb frequency (entrenchment) on children's and adults' graded judgements of argument-structure overgeneralisation errors. Cognition 106, 87-129.

Astington, J.W., Jenkins, J.M., 1999. A longitudinal study of the relation between language and theory-of-mind. Developmental Psychology 35, 1311-1320.

Bartsch, K., Wellman, H.M., 1995. Children Talk about the Mind. Oxford University Press, New York.

Brandt, S., Liven, E.V.M., Tomasello, M., unpublished manuscript. The acquisition of finite complement clauses in German: a case study. Max Planck Institute for the Evolutionary Arthropology.

Bresnan, J., 2001. Lexical-Functional Syntax. Blackwell, Oxford.

Brooks, P.J., Tomasello, M., Dodson, K., Lewis, L.B., 1999. Young children's overgeneralizations with fixed transitivity verbs. Child Development 70, 1325-1337.

Casenhiser, D., Goldberg, A.E., 2005. Fast mapping between a phrasal form and meaning. Developmental Science 8, 500-508.

Dabrowska, E., Rowland, C., Theakston, A,. 2009. The acquisition of questions with long-distance dependencies. Cognitive Linguistics.

Diessel, H., 2004. The Acquisition of Complex Sentences. Cambridge University Press, Cambridge, UK.

Diessel, H., Tomasello, M., 2001. The acquisition of finite complement clauses in English: a corpus-based analysis. Cognitive Linguistics $12,97-141$.

Garnsey, S., Pearlmutter, M., Myers, E., Lotocky, M.A., 1997. The contributions of verb bias and plausibility to the comprehension of temporarily ambiguous sentences. Journal of Memory and Language 37, 58-93.

Goldberg, A.E., 1995. Constructions: A Construction Grammar Approach to Argument Structure. Chicago University Press, Chicago.

Goldberg, A.E., 2006. Constructions at Work: The Nature of Generalization in Language. Oxford University Press, Oxford.

Goldberg, A.E., Casenhiser, D.M., Sethuraman, N., 2004. Learning argument structure generalisations. Cognitive Linguistics 15, $289-316$.

Goldberg, A.E., Casenhiser, D.M., Sethuraman, N., 2005. Role of prediction in construction learning. Journal of Child Language 32, 407426.

Holmes, V.M., Stowe, L., Cupples, L., 1989. Lexical expectations in parsing complement-verb sentences. Journal of Memory and Language 28, 668-689.

Kidd, E., 2006. The acquisition of complement clause constructions. In: Clark, E.V., Kelly, B.F. (Eds.), Constructions in Acquisition. CSLI Publications, Stanford, CA, pp. 311-331.

Kidd, E., Lieven, E.V.M., Tomasello, M., 2006. Examining the role of lexical frequency in children's acquisition of sentential complements. Cognitive Development 21, 93-107.

Langacker, R., 2000. A dynamic usage-based model. In: Barlow, M., Kemmer, S. (Eds.), Usage-Based Models of Language. CSLI Publications, Stanford, pp. 1-63.

Levin, B., 1993. English Verb Classes and Alternations: A Preliminary Investigation. University of Chicago Press, Chicago.

Lieven, E.V.M., Pine, J., Baldwin, G., 1997. Lexically-based learning and early grammatical development. Journal of Child Language 24, 187-220. 
MacDonald, M.C., Pearlmutter, N.J., Seidenberg, M.S., 1994. Lexical nature of syntactic ambiguity resolution. Psychological Review 101, 676-703.

MacWhinney, B., 1998. Models of the emergence of language. Annual Review of Psychology 49, 199-227.

MacWhinney, B. (Ed.), 2000. The CHILDES Project: Tools for Analysing Talk, vol. 1. Erlbaum, Mawah, NJ.

Matthews, D., Lieven, E., Theakston, A.L., Tomasello, M., 2005. The role of frequency in the acquisition of English word order. Cognitive Development 20, 121-136.

Matthews, D., Lieven, E.V.M., Theakston, A.L., Tomasello, M., 2007. French children's use and correction of weird word orders: a constructivist account. Journal of Child Language 34, 381-409.

McClure, K., Pine, J.M., Lieven, E.V.M., 2006. Investigating the abstractness of children's early knowledge of argument structure. Journal of Child Language 33, 693-720.

Pollard, C., Sag, I., 1994. Head-Driven Phrase Structure Grammar. Chicago University Press, Chicago.

Theakston, A.L., 2004. The role of entrenchment in children's and adult's performance on grammaticality judgment tasks. Cognitive Development 19, 15-34.

Theakston, A.L., Lieven, E.V.M., Pine, J.M., Rowland, C.F., 2001. The role of performance limitations in the acquisition of verb argument structure. Journal of Child Language 28, 127-152.

Thompson, S., 2002. Object complements and conversation. Towards a realistic account. Studies in Language 26, $125-164$.

Thompson, S.A., Mulac, A., 1991. The discourse conditions for the use of the complementizer 'that' in conversational English. Journal of Pragmatics 15, 237-251.

Tomasello, M., 2000. Do young children have adult syntactic competence? Cognition 74, 209-253.

Tomasello, M., 2003. Constructing a Language: A Usage-based Theory of Language Acquisition. Harvard University Press, Cambridge, MA.

Trueswell, J.C., Tanenhaus, M.K., (1994). Toward a lexicalist framework for constraint-based syntactic ambiguity resolution. In: Clifton, C., Frazier, L., Rayner, K. (Eds.), Perspectives in Sentence Processing. Lawrence Erlbaum Assoc., Hillsdale, NJ, pp. $155-179$.

Trueswell, J.C., Tanenhaus, M.K., Kello, C., 1993. Verb-specific constraints in sentence processing: separating effects of lexical preference from garden- paths. Journal of Experimental Psychology: Learning, memory and Cognition 19, 528-553.

Verhagen, A., 2005. Constructions of Intersubjectivity. Oxford University Press, Oxford. 